\title{
Improved methods of complex estimation of efficiency of activity of industrial organizations
}

\author{
E.H. Taipova ${ }^{1}$, Y.V. Lysenko ${ }^{1}$, and T.N. Myznikova ${ }^{1, *}$ \\ ${ }^{1}$ South Ural State University, Chelyabinsk, Russia
}

\begin{abstract}
The article substantiates the need for combined technological, technical, financial and economic indicators that characterize the efficiency of production and economic activity of an industrial enterprise. Stages of performance evaluation: from single to integrated assessment criteria. It named the main drawback of the existing methods of constructing a system of indicators, which leads to subjectivity, to a lack of real understanding of the financial and economic state of the industrial organization. It is shown that multivariate statistical methods of classification can not only minimize their number, but also to detect correlations for each cluster, as well as to build a multi-factor regression models, which are the basis of perfection of a technique of an integrated approach to assessing the results of functioning of the organization. Thus, the algorithm for determining the integral index of evaluating the performance of the company contributes to an objective vision of the ways to improve operational and financial performance of industrial organizations.
\end{abstract}

\section{Introduction}

The relevance of this article lies in the fact that the increase of efficiency of functioning of industrial organizations - one of the most important economic problems, the solution of which depends on the level of development of the industrial sector, and hence the rise of living standards of the population. To solve this problem is impossible without substantial investment and development of innovative technologies. Primarily, it refers to a precocious, high technology and high-tech industry, as the industry.

To support the industry and its transition to an innovative path of development it is important to ensure rational use of available resources and internal reserves to increase production, improve the efficiency and competitiveness of the industry's products. An integrated approach to solving a wide range of issues relating to the justification of the priorities of reconstruction and further development of the industry. This approach is based on an objective and comprehensive assessment of the processes, the aim of which is to determine the state of the organization and the potential for their further development.

Modern economics offers a variety of methodology for assessing the effectiveness of using a significant amount of production and financial performance. But, as practice shows, such orientation adversely affect the adoption of the strategic and operational management decisions leaders, which is difficult to navigate in a variety of disparate indicators and their derivatives financial ratios.
Thus, the issue of improving the assessment of efficiency of functioning of industrial organizations in modern conditions becomes relevant.

Hence the purpose of this article is to develop an algorithm for evaluating the performance of industry organizations.

\section{Approaches to the assessment of performance industry organizations}

The theoretical analysis of the effectiveness of methods for assessing the activities of industry organizations has identified the following stages: an initial assessment carried out by a single criteria, then was used a system of indicators, at the present stage apply integrated assessment, obtained by the methods of multivariate analysis (Figure 1). [1, 2, 15 ].

In the first stage we have been allocated such individual factors as profit margins. But these figures do not allow to fully and objectively evaluate the effectiveness of the functioning of institutions, as their selection is carried out at random, based on the subjective views and preferences of analysts on the importance of certain criteria. Accordingly, the selected criteria do not reflect the real state of the organization, do not allow to build a reasonable forecast of its development.

The next step is evaluation of the functioning of organizations has become based on the use of indicators. However, at present there is no universal system of common indicators to obtain a unique solution. This is due to the fact that all organizations 
have their particular industry. Therefore, evaluation of the effectiveness of activities designed only for a defined range of administrative tasks (identification of credit, drawing up the strategic development plan, receiving the auditor's report, etc.), carried out on the basis of a particular situation.

In addition, the main drawback of currently existing methods of constructing a system of indicators is that the selection criteria carried out by experts. Hence, the subjectivity of the results, the lack of real understanding of the situation in the organizations, which complicates the work of the analyst. At the same time the desire of some of the authors included in the measurement of assessing the effectiveness of as many indicators are not always justified, as a number of indicators often duplicate each other, and some of them do not carry the semantic load.

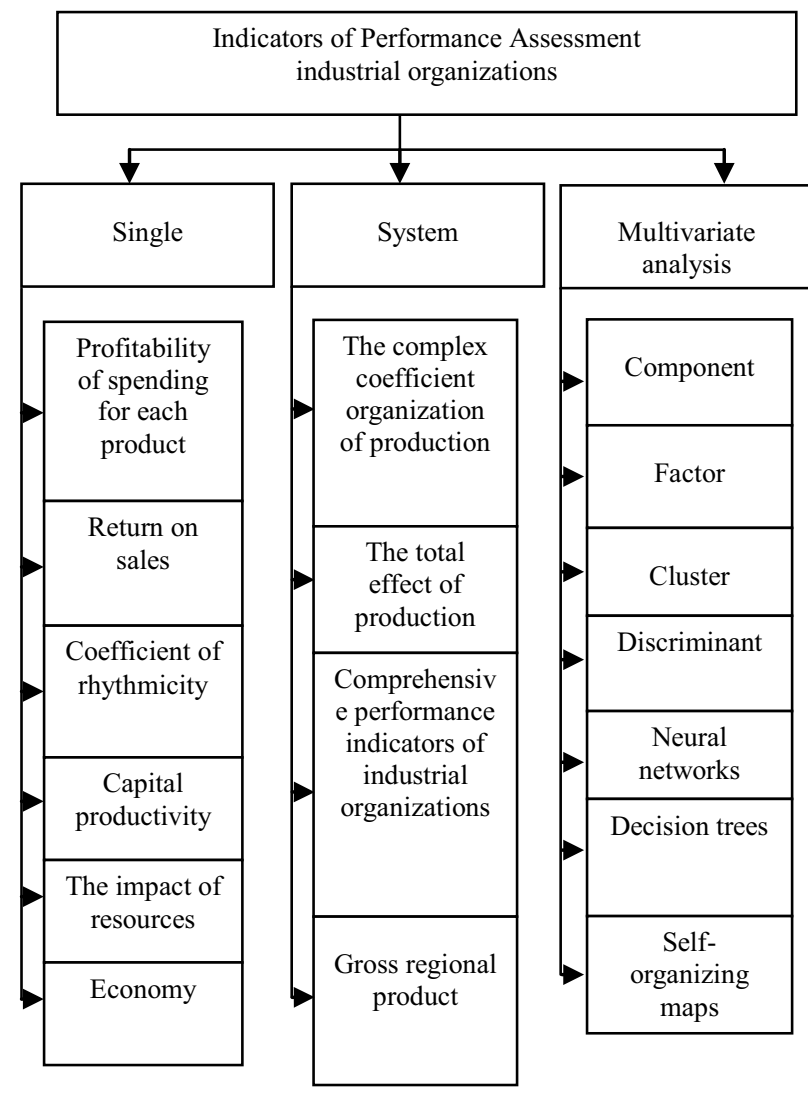

Fig. 1. Classification of methodological approaches to the assessment of the effectiveness of the industry organizations.

Our studies show that at the present stage to remove all the deficiencies noted: bias, subjectivity and one-sidedness - the procedure allows the calculation of the integral index, the methodological basis for the formation of which is multidimensional analysis. Methods cluster, discriminant, factor, component, and other types of analysis allow you to search and find out unlimited, heterogeneous and dispersed information unobvious and complex patterns, to acquire new knowledge. Thus, the integral value obtained by the methods of multivariate analysis, makes it possible, in contrast to the prior art, not only to assess the effectiveness of the organization, but also to suggest ways of its development, see the directions of optimization of management and production structures to build a competent marketing and investment politicians.

\section{Cluster analysis}

The main method to categorize multivariate observations is cluster analysis, with which you can break the set of monitored parameters of the set of industrial organizations into homogeneous subsets $[3,13,11]$.

Data territorial body of the Federal Service on the performance of industrial companies within five years of the state statistics of the Chelyabinsk region is used as a source of information. In order to avoid distortion of the results of cluster analysis of the influence of baseline measurement units last were normalized in terms of "revenue from sales of products." Dendrogram conducted multivariate classification is shown in Fig. 2, where it is possible to distinguish three typological groups of industrial organizations of Chelyabinsk region $[4,5,9]$.

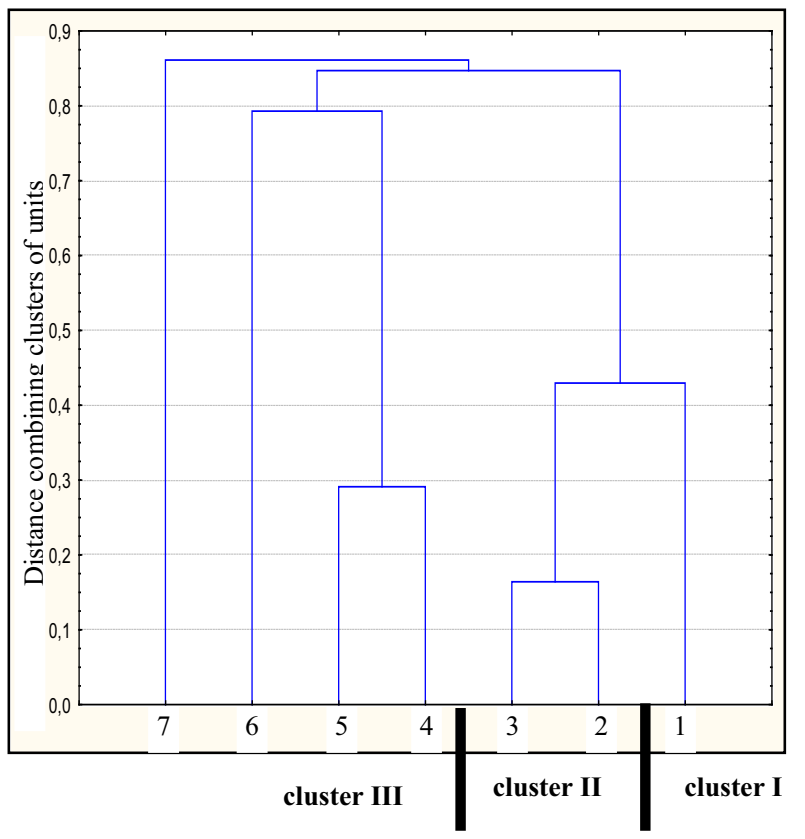

Fig. 2. Dendrogram multidimensional classification of industrial organizations: 1 - OJSC "Chelyabinsk Tube Rolling Plant"; 2 - JSC "Trubodetal"; 3 - OJSC "Chelyabinsk Metallurgical Plant"; 4 - OJSC "Chelyabinsk Mechanical Plant"; 5 - JSC "Chelyabinsk Compressor Plant"; 6 - LLC "Chelyabinsk Tractor Plant - URALTRAC"; 7 - OJSC "Chelyabinsk Forging Plant".

Cluster I comprises a single organization, which is one of the major industrial producers in the area: "Chelyabinsk Tube Rolling Plant". This cluster is characterized by high levels of efficiency of its functioning.

Cluster II combines objects traditionally produced in terms of the effectiveness of secondary evaluation and having an average competitiveness. It includes OAO "Chelyabinsk Metallurgical Plant" and OJSC "Chelyabinsk Mechanical Plant". 
Cluster III concentrates a remaining industrial organizations. This group is characterized by low efficiency of activity: the simple process of reproduction it is not provided.

\section{The discriminant analysis of multiple}

The resulting group typical industrial organizations were subjected to further study using the statistical analysis of multiple discriminant, the essence of which is that between the selected variable characteristics and grouping correlation set. Thus, for each cluster we identified five relevant variables (Table 1) which determine the efficiency product [6, $12,20]$.

Table 1. Indicators that determine the efficiency of the industrial organizations on the results of the discriminant analysis.

\begin{tabular}{|c|c|c|c|c|}
\hline Indicator & \multirow{2}{*}{$\begin{array}{c}\text { Cipher } \\
\text { indicator }\end{array}$} & \multicolumn{3}{|c|}{ Cluster } \\
\cline { 3 - 5 } & $X_{1}$ & + & + & + \\
\hline $\begin{array}{c}\text { The volume of gross } \\
\text { output, cond. u }\end{array}$ & $X_{2}$ & + & + & + \\
\hline $\begin{array}{c}\text { The volume of } \\
\text { commodity products, } \\
\text { cond. u }\end{array}$ & $X_{3}$ & + & + & + \\
\hline $\begin{array}{c}\text { Production costs, rub. } \\
\text { / Conventional units. }\end{array}$ & $X_{4}$ & + & + & + \\
\hline $\begin{array}{c}\text { The complexity of } \\
\text { production, man-hours } \\
\text { / conventional units. }\end{array}$ & $X_{5}$ & + & + & + \\
\hline $\begin{array}{c}\text { The volume of } \\
\text { shipped products, } \\
\text { cond. u }\end{array}$ & $X_{6}$ & - & - & - \\
\hline $\begin{array}{c}\text { Time between unit } \\
\text { product, min }\end{array}$ & $X_{7}$ & & & \\
\hline Unit Weight, t & $X_{8}$ & - & - & - \\
\hline $\begin{array}{c}\text { The production cost of } \\
\text { one standard unit of } \\
\text { production, rbl. }\end{array}$ & $X_{10}$ & - & - & - \\
\hline $\begin{array}{c}\text { The average number } \\
\text { of employees, people. }\end{array}$ & $X_{9}$ & - & - & - \\
\hline $\begin{array}{c}\text { The volume of sales, } \\
\text { cond. u }\end{array}$ & $X_{10}$ & - & - \\
\hline $\begin{array}{c}\text { The average selling } \\
\text { price, rub. / } \\
\text { Conventional units. }\end{array}$ & $\begin{array}{c}\text { Cost of sales, rub. / } \\
\text { Conventional units. }\end{array}$ & $X_{12}$ & - & - \\
\hline
\end{tabular}

Checking the closeness of the connection between the derived variables (multicollinearity) based on the analysis of the matrix of paired correlation coefficients allowed to exclude from further calculation of a number of indicators: the gross output (X1) and the volume of commodity output (X2), as their simple correlation coefficients were more than 0.8 .

To show the impact of the remaining indicators: production cost (X3), the complexity of production (X4), the volume of products shipped (X5) - the financial results of activity of the organizations of each cluster (YI, II, III) were constructed multivariate regression models of industrial organizations focused for-profit (Table 2).

Table 2. Regression models of industrial companies focused on making a profit.

\begin{tabular}{|c|c|c|}
\hline $\begin{array}{c}\text { Cluster } \\
\text { number }\end{array}$ & The regression equation & $\begin{array}{c}\text { Coeffi } \\
\text { cient } \\
\text { determi } \\
\text { nation } \\
\left(R^{2}\right)\end{array}$ \\
\hline I & $\begin{array}{c}Y_{I}=-0,42-0,38 X_{3}+1,30 X_{4}+0,74 X_{5} \\
2215<X_{3}<4933 ; 3<X_{4}<10 ; 291 \\
<X_{5}<421\end{array}$ & 0.953 \\
\hline II & $\begin{array}{c}Y_{I I}=2,49+0,33 X_{3}-0,63 X_{4}-2,28 X_{5} \\
4272<X_{3}<5306 ; 6<X_{4}<13 ; 360 \\
<X_{5}<419\end{array}$ & 0.875 \\
\hline III & $\begin{array}{c}0,21 X_{5} \\
Y_{I I I}=-1,25-0,65 X_{3}+1,44 X_{4}-\end{array}$ & \\
& $\begin{array}{c}9716<X_{3}<19167 ; 75<X_{4}<118 ; 88 \\
<X_{5}<226\end{array}$ & 0.726 \\
\hline
\end{tabular}

According to Table. 2 You can make the following conclusions.

In a cluster I profit organizations, achieved through a combination of intensive and extensive factors of production. This is evidenced by the fact that the financial result is determined by a decrease in the cost per unit of production and increasing the complexity.

In cluster II the growth of a productive indicator opposite situation cluster I. Algebraic signs with phrases X3 and X5 indicate the extensive nature of production and, moreover, inefficient use of resources.

A characteristic feature of cluster III is a surplus of labor force, as reflected in the resulting regression model. Use in this segment, as compared to other, larger proportion of human labor in conjunction with the inefficient use of resources makes manufacture unprofitable.

In general it can be noted that the industrial organization of the Chelyabinsk region at the moment, except for a few large ones, do not focus on the application of innovative technologies for the reduction of material, energy and labor resources in the production process $[7,14,19]$.

\section{Algorithm for Integral indicators of organizational performance}

The developed algorithm for estimating the efficiency of organizations in industry involves the following steps (Fig. 3) [8, 16, 18].

The developed algorithm is adapted to the industrial Chelyabinsk area institutions. Values levels intervals determined according to step 7 shown in Table 3. 
Table 3. Qualifier detection level range of performance indicators.

\begin{tabular}{|c|c|c|c|c|c|}
\hline \multirow{2}{*}{ Indicator } & \multicolumn{5}{|c|}{ Level range } \\
\cline { 2 - 6 } & Very low & Low & Average & Tall & Very tall \\
\hline $\mathrm{X}_{1}$ & $\mathrm{x}_{1}<8300$ & $8300<\mathrm{x}_{1}<16600$ & $16600<\mathrm{x}_{1}<24900$ & $24900<\mathrm{x}_{1}<33200$ & $33200<\mathrm{x}_{1}$ \\
\hline $\mathrm{X}_{2}$ & $\mathrm{x}_{2}<60$ & $60<\mathrm{x}_{2}<120$ & $120<\mathrm{x}_{2}<180$ & $180<\mathrm{x}_{2}<240$ & $240<\mathrm{x}_{2}$ \\
\hline Weights levels & 0.9 & 0.7 & 0.5 & 0.3 & 0.1 \\
\hline $\mathrm{X}_{3}$ & $\mathrm{x}_{3}<102$ & $102<\mathrm{x}_{3}<204$ & $204<\mathrm{x}_{3}<306$ & $306<\mathrm{x}_{3}<408$ & $408<\mathrm{x}_{3}$ \\
\hline Weights levels & 0.1 & 0.3 & 0.5 & 0.7 & 0.9 \\
\hline
\end{tabular}

The results of evaluating the performance of industrial enterprises of the Chelyabinsk region are presented in Table 4.

Table 4. Determination of the effectiveness of the type of Industrial Organizations.

\begin{tabular}{|c|c|c|c|c|c|}
\hline \multirow[b]{2}{*}{$\begin{array}{l}\text { Name Industrial } \\
\text { Organization }\end{array}$} & \multicolumn{3}{|c|}{ Existing indicators } & \multirow[b]{2}{*}{ 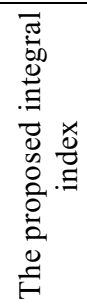 } & \multirow[b]{2}{*}{ 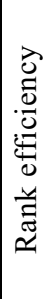 } \\
\hline & $\begin{array}{l}00 \\
.0 \\
.00 \\
\tilde{\Xi} \\
\Xi \\
\tilde{\omega} \\
0 \\
0\end{array}$ & 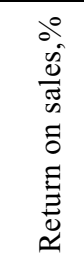 & 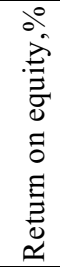 & & \\
\hline $\begin{array}{l}\text { "Chelyabinsk } \\
\text { Tube Rolling } \\
\text { Plant" }\end{array}$ & 34 & 40 & 39 & $\begin{array}{c}0.82 \\
5\end{array}$ & 5 \\
\hline JSC "Trubodetal" & 3 & 3 & 1,3 & $\begin{array}{c}0.75 \\
9\end{array}$ & 4 \\
\hline $\begin{array}{c}\text { OJSC } \\
\text { "Chelyabinsk } \\
\text { Metallurgical } \\
\text { Plant" }\end{array}$ & 26 & 21 & 2 & $\begin{array}{c}0.76 \\
1\end{array}$ & 4 \\
\hline $\begin{array}{c}\text { "Chelyabinsk } \\
\text { Mechanical Plant" }\end{array}$ & $-1,2$ & $-0,7$ & 0 & $\begin{array}{c}0.23 \\
5\end{array}$ & 2 \\
\hline $\begin{array}{c}\text { CJSC } \\
\text { "Chelyabinsk } \\
\text { Compressor } \\
\text { Plant" } \\
\end{array}$ & -63 & -168 & -4 & $\begin{array}{c}0.09 \\
9\end{array}$ & 1 \\
\hline $\begin{array}{c}\text { LLC } \\
\text { "Chelyabinsk } \\
\text { Tractor Plant - } \\
\text { URALTRAC" }\end{array}$ & -19 & -24 & 0 & $\begin{array}{c}0.69 \\
3\end{array}$ & 4 \\
\hline $\begin{array}{c}\text { OJSC } \\
\text { "Chelyabinsk } \\
\text { Forge-and-Press } \\
\text { Plant" }\end{array}$ & -74 & -285 & -1 & $\begin{array}{c}0.23 \\
1\end{array}$ & 2 \\
\hline
\end{tabular}

According to the traditional method of evaluating the performance of only three organizations are positive margins.

In developed algorithm, one industrial organization has a high level of efficiency of functioning - OJSC "Chelyabinsk Tube Rolling Plant". Above average level of efficiency of functioning "Trubodetal", OJSC "Chelyabinsk Metallurgical Plant" and JSC "Chelyabinsk Tractor Plant - URALTRAC". Stragglers - by a combined indicator of efficiency of operation of less than 0.3 are the three companies within the cluster III: "Chelyabinsk Mechanical Plant", JSC "Chelyabinsk Compressor Plant", OJSC "Chelyabinsk Forging Plant".
This algorithm for determining the integral index of functioning efficiency evaluation reveals the real

potential of the organization. The special significance of the proposed algorithm is that it can help managers can see ways of improving operational and financial performance, and potential investors receive a tool to see the investment attractiveness of the interest of their organizations $[10,17]$.

\section{Conclusion}

1. The tendency to assess the effectiveness of industrial enterprises shows the transition from the simple use of disparate criteria that describe the technological, technical, economic, financial and other state organizations, to the integral index, obtained by the methods of multivariate analysis, formed taking into account all the characteristics of the variety, typical of large economic systems, under which can be understood as a branch, and individual industry organizations.

2. Conduct a cluster analysis allowed to divide the totality of these objects into three groups, characterized by homogeneity, the presence of common problems and similar disabilities affecting the results of operations.

Using discriminant analysis, combined with a procedure to eliminate the multicollinearity between the indices has made it possible for each cluster to identify those that best meet the objective of increase of productivity of functioning of industrial organization through identified indicators: production cost, labor intensity of production, the volume of products shipped.

3. The use of multivariate analysis has allowed a high degree of reliability of approximation to construct multivariate regression models. The analysis identified the characteristics of combinations made it possible to establish their optimal values that maximize the financial results for each cluster.

An algorithm for evaluating the performance of industrial enterprises on the basis of a multidimensional approach to recording industry characteristics, which allows you to get the value of the integral index and determine the type of organizational effectiveness. In addition, the resulting criterion allows to reflect the real potential of the existing organization and enables public authorities and municipal governments, as well as prospective investors to make informed management decisions to improve the efficiency of the business entity. 


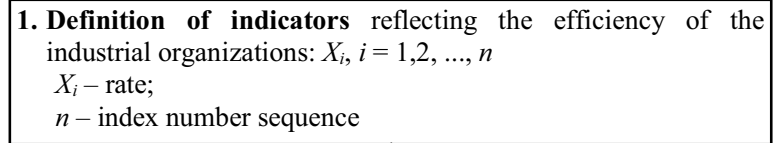

2. Scaling performance (bringing disparate indicators in a comparable form): $X_{i}^{H}=\frac{X_{i}}{X_{\mathrm{i} \max }}$,

where $X_{i}$ - the actual value of the indicator;

$X_{\max }-$ maximum value of the $i$-th index

3. Conduct discriminant analysis - the main means of solving
problems of pattern recognition, which is used for deciding
which variables are separated (ie, "discriminate") arising from
the data sets:
\[ \ni=f\left(X_{1}^{H} ; X_{2}^{H} ; \ldots, X_{n}^{H}\right) \]

4. Elimination of multicollinearity (when the pair correlation coefficient greater than 0.8): $\ni=f\left(X_{3}^{H} ; X_{4}^{H}, X_{5}^{H}\right)$

\begin{tabular}{|c|c|c|c|c|c|}
\hline \multicolumn{6}{|c|}{$\frac{1}{\nu}$} \\
\hline \multicolumn{6}{|c|}{$\begin{array}{l}\text { 5. Determination of the level of significance } r \text { : } \\
\qquad r_{i j}=\frac{1}{n_{i j}} \\
\text { where } r_{i j} \text {-significance level } i \text {-th index in the } j \text {-th interval; } \\
n_{i j}-\text { sequence number of } i \text {-th index in the } j \text {-th interval. }\end{array}$} \\
\hline \multicolumn{6}{|c|}{ 6. Formation interval level classifier performance: } \\
\hline \multirow{2}{*}{ Indicator } & \multicolumn{5}{|c|}{ Level range } \\
\hline & 1 & 2 & 3 & 4 & 5 \\
\hline $\mathrm{X}_{\mathrm{i}}^{\mathrm{H}}$ & Very low & Low & Average & Tall & Very tall \\
\hline
\end{tabular}

7. Determination of the length of the interval $I$ of each indicator:

$$
I_{i}=\frac{x_{i \max }^{H}-x_{i \min }^{H}}{5}
$$

8. Calculation of the integral efficiency index $K$ :

$$
K=\sum_{i=1}^{n} \sum_{j=1}^{m} g_{i j} \cdot r_{i j} \cdot \lambda_{i j},
$$

where $\lambda_{i j}$ - quality value of $i$-th index in the $j$-th interval,

$\lambda \in(0 ; 1)$;

$g_{i j}$ - weighting factor $i$-th index in the range of $j$-th, $g=0-1$.

\begin{tabular}{|c|c|l|}
\hline $\begin{array}{c}\text { 9. Determination of } \\
\text { effectiveness: }\end{array}$ & \multicolumn{1}{|c|}{ the type of organizational } \\
\hline $\begin{array}{c}\text { Range of values } \\
\text { integral index }\end{array}$ & Rank & $\begin{array}{c}\text { Type } \\
\text { effectiveness }\end{array}$ \\
\hline $0.0-0.2$ & 1 & low limit \\
\hline $0.2-0.4$ & 2 & Low \\
\hline $0.4-0.6$ & 3 & Average \\
\hline $0.6-0.8$ & 4 & $\begin{array}{l}\text { Above } \\
\text { average }\end{array}$ \\
\hline $0.8-1.0$ & 5 & High \\
\hline
\end{tabular}

Fig. 3. The algorithm for evaluating the performance of industrial organizations.

The work was supported by Act 211 Government of the Russian Federation, contract № 02.A03.21.0011.

\section{References}

1. V.V. Joffe, Estimation of economic stability of industrial enterprise (Irkutsk, 2005)

2. V.M. Simchera, Methods of multivariate statistical data analysis (Finance and Statistics, Moscow, 2008)

3. M.V. Bushmanova, T.A. Dubrova, N.A. Mochalkin, Cluster analysis. Conducting multivariate classification methods of observation of cluster analysis in "Statistica" package (Bauman, Magnitogorsk, 2002)

4. Chelyabinsk region: Statistical Yearbook, the Federal State Statistics Service, the territorial body of the Federal State Statistics Service of the Chelyabinsk region (2008)

5. Scenario conditions for the functioning of the Russian economy, the basic parameters of the forecast of social and economic development of the Russian Federation for 2016 and the planning period of 2017 and 2018

6. S.A. Nedosekin, Audits and financial analysis, 2, (2000)

7. P. Fishburne, Utility theory for decision-making (Science, Moscow, 1978)

8. S.A. Nedosekin, O.B. Maksimov, The new comprehensive index evaluation of the enterprise financial condition. http://sedok.narod.ru/sc_group.html.

9. V.I. Guard, Analysis of economic activity in the industry (High School, Minsk, 2005)

10. I. Prokopenko, K. Nort, Performance management and quality modular program, in 2 hours (Case, Moscow, 2001)

11. A.M. Dubrov, V.S. Mkhitaryan, L.I. Troshin, Multivariate statistical methods (Moscow, Finance and Statistics, 1998).

12. A. Khalafyan, Industrial Statistics. Quality control, process analysis, design of experiments in the package STATISTICA (LIBROKOM, Moscow, 2013)

13. R. Kaplan, D. Norton, The Balanced Scorecard. From strategy to action (Business Olympus, Moscow, 2008)

14. A.M. Pearls, M.K. Pearls, Russian Entrepreneurship, 6, 2, (2010)

15. I.V. Matyas, Math. ASU, 2-1(66), 253-262 (2010)

16. A. Vasiliev, Integral indicator of the efficiency of economic activity of the enterprise. http // ekonomika.ru.

17. E.M. Panevina, Russian Entrepreneurship, 11, 2(147), 56-62 (2009)

18. T. Copeland, T. Koller, D. Murrin, The cost of companies. Assessment and Management (Business Olympus, Moscow, 2008)

19. EVA \& Strategy. Stern Stewart \& Co. Research. The Americas, 4, (2000).

20. Rappaport, Creating shareholder value: a guide for managers and investors (Free Press, New York, 1998) 